\title{
Using Peer-Shared Intervention Strategies for Promoting Math Explorations and Critical Thinking in Early Childhood Inclusive Classrooms
}

\author{
Kathleen I. Harris \\ Correspondence: Kathleen I. Harris, School of Education and Applied Social Sciences, Seton Hill University, \\ Greensburg, Pennsylvania, USA.
}

Received: January 8, 2019

doi:10.11114/ijce.v2i1.3950

\author{
Accepted: February 11, $2019 \quad$ Online Published: February 19, 2019 \\ URL: https://doi.org/10.11114/ijce.v2i1.3950
}

\begin{abstract}
Inclusive early childhood settings invite children with and without disabilities to play, learn, and work together in one classroom. Teachers can take advantage of children's curiosity for math when they organize creative learning environments and develop meaningful critical thinking experiences to increase children's interactions with peers. Peer-shared activities, including math helpmates and math chats, can offer a hopeful approach for supporting higher order and critical thinking math experiences for young children in inclusive classroom settings. Inviting a math helpmate to explain to a peer how or why they arrived at an answer or to show a different way to find an answer during math activities can promote critical math thinking and communication skills. To maximize success when using peer-shared strategies, teachers should be actively involved in monitoring math progress, providing feedback to children, and supporting peer interactions. This article will explore a variety of strategies for creating math discoveries and critical thinking using peer-shared activities at school and home. Practical strategies to be discussed will include math helpmates, math chats, and incidental teaching for increasing for supporting children's natural interest in math concepts.
\end{abstract}

Keywords: math, peers, early childhood, strategies, critical thinking, incidental teaching

\section{Introduction}

Children's acquisition of formal mathematics and mathematical operations (i.e., rote counting, counting as meaning, one-to-one correspondence, and numeral operations) is related to the broad ability of quantitative knowledge (Lynch \&Warner, 2013). Teachers can take advantage of children's curiosity for math when they organize hands-on, creative learning environments and develop meaningful experiences to increase children's interactions with peers. Because of this, early childhood is the ideal time for children to experience and discover math. For example, young children cultivate ideas about mathematics in the course of their day-to-day lives quite naturally (Epstein, 2014). They explore mathematical dimensions by looking for patterns, shapes, sizes, and comparing quantities at home, school, and in the community. However, research indicates the typical early childhood curriculum includes limited exposure to thoughtful and intentional mathematics experiences (Copley, 2004). To challenge this, the goal of mathematics for early childhood should be building mathematical power in young children by creating an awareness of mathematical concepts and skills (Epstein, 2014). The National Council of Teachers of Mathematics (NCTM, 2013) proclaims early childhood educators should aggressively introduce mathematical concepts, methods, and language through a selection of appropriate experiences and evidence-based teaching strategies. Teachers also need to be sensitive to this because today classrooms are more diverse than ever and young children have diverse needs. Inclusive early childhood settings invite children with and without disabilities to play, learn, and work together in one classroom. One way to encourage awareness is by increasing opportunities for peer-shared activities during math play and instruction.

\section{Peer-shared Activities}

Mathematical knowledge is socially constructed and fostered by positive social interactions (Bahr \& deGarcia, 2010). Among the skills and knowledge early childhood educators support and promote, many of the essential skills include emotional awareness, initiative, and positive social behaviors (Jackson, 2012). The importance of developing both social and academic proficiency is reflected in standards for learning for early childhood (Diamond, Hong, \& Baroody, 2008). In order to ensure a successful future development in educational and social environments, a child must develop proficient social behaviors (Platas, 2017; Saunders \& Green, 1993). Social interactions support young children in a variety of 
settings and with a number of people (Terpstra \& Tamura, 2008). For example, within social interactions, young children develop verbal skills to turn take with peers, encourage one another, work collaboratively and cooperate with peers, practice following rules and form friendships with peers. When children have opportunities to share hypothesis, question one another, elaborate and examine math problems, and are challenged by their decisions regarding a math equation, critical thinking often sparks engagement, new considerations to problems, and solutions. As a result, young children are learning both math and social skills. Researchers stress the critical role of positive peer relationships in childhood (Ladd, 2007). Young children learn and increase their understanding of numbers as they encounter new and multiple number experiences that challenge their previous understandings (Baroody, Lai, \& Mix, 2006; Wakefield, 1997; Zaslow, 2014). As a result, it is important for teachers to encourage children to communicate about their mathematical ideas and learn how their peers think about a problem. When early childhood inclusive classrooms establish an informal mathematical learning community, children can share and examine their ideas with each other (Jung \& Conderman, 2015).

For young children, learning occurs within everyday exchanges (Bodrova \& Leong, 1996). Ideality, this is the beginning step to peer-sharing activities. Peer-shared activities provide a resource of providing assistance to children when learning a new skill. Peer-shared activities can construct a framework within which interactions among children are encouraged, facilitated, and supported in classroom settings (Carter, Cushing \& Kennedy, 2009). Theorist, Lev Vygotsky, ideas about shared activity and its role in development include many kinds of interactions between two or more participants (Solomon, 1993). Thus, shared activity is a means of providing the assistance children require at the higher levels of the Zone of Proximal Development (ZPD). The ZPD has two levels; the lowest level is what a child can do independently and the highest level is what the child can do with maximum assistance (Bodrova \& Leong, 1996). During the shared activity, the social interactions with peers supports and acts as a motivator for assistance at the highest levels of ZPD (Bodrova \& Leong, 1996). Without the language or interactions with peers, sharing or communication building skills will not produce the highest assistance possible. Positive peer relationships play an important role in fostering a sense of community in the classroom and encouraging academic productivity and prosocial behavior for all children (Elias \& Dilworth, 2003). Peer-shared activities can encourage children to be in close proximity and actively involved in interactive math activities.

To motivate learning and initiate interaction for behaviors that are on the edge of emergence, children should participate in very specific types of peer interactions (Bodrova \& Leong, 1996). For example when young children interact with peers, it could be concerning friendships and past interactions either at home or school. By organizing the math objective and skill to be accomplished with the proper environment and learning materials as top priorities, (for example, Unifix blocks, geoboards, clocks, dominoes, shape sorters, open-ended art materials, balance scales, and puzzles) meaningful math experiences and learning can take place. Sharing new ideas, even uncertainty during problem solving, may prompt children to articulate and transform their math understanding with other peers (Epstein, 2014). Numerous studies have suggested that student-to-student interactions, such as peer-shared activities, have as much or more impact on the quality of classroom climate than teacher-student interactions (Emmer \& Gerwels, 2002). Peers may motivate stronger responses when working in close proximity to another child needing support (Giberts, Agran, Hughes, \& Wehmeyer, 2001).

\section{Math Helpmates}

Math helpmates' is a teaching strategy that compliments teachers' instructions in the classrooms while meeting the unique needs of children. On many occasions, young children can sometimes explain mathematical ideas to their peers more effectively than adults (Epstein, 2014). Math helpmates can individualize instruction for a child needing extra support with math allowing the child to practice critical thinking and work at his or her own pace and level of understanding. Math helpmates can also suggest materials that pertain to a child's interest and provide visual cues that can support and promote social interactions. Because using math helpmates for peer-shared activities is teacher and child-friendly and flexible for teachers, they can fit into instructional times and needs of each child. Most children become involved in peer-shared activities because they recognize it is another exciting opportunity to develop a new friendship with one of their classmates (Carter, Cushing, \& Kennedy, 2009).

Math helpmates can support children with a variety of problem solving activities such as asking open-ended questions to make predictions, estimating and posing questions about sizes of objects, helping children count by ones and twos, using one-to-one correspondence and taking turns by putting puzzles together or taking turns and playing board games. Open-ended questions guides and promotes young children to talk about their decision-making strategies (Tyminski \& Linder, 2012). Young children's math problem-solving skills also demonstrate a component of social competence (Denham, Blair, Demulder, Levitas, Sawyer, \& Auerbch-Mayor, 2003). As a result, peer problem-solving skills can be used in many social environments and may strengthen peer interactions and relationships. For example, during an interactive and hands-on pattern math carnival in an early childhood inclusive classroom, a math helper could model 
ways for another child to create an $\mathrm{AB}$ pattern with colored dots on a clown template. A math helpmate could prompt a child by placing the correct color dot to finish an arc above the clown to represent the colored balls being juggled. In addition, math helpmates can help solve problems that may arise for a child by building new mathematical knowledge through problem solving strategies. During the same event, children may have the opportunity to create additional new patterns using matching lengths of yarn for hot dogs and hamburgers for a carnival picnic. A math helpmate could assist another child with creating an A, B, C patterns by adding "yarn" condiments to create a pattern for a hot dog or hamburger. Examples would be red yard for ketchup; yellow yarn for mustard, and green yarn for relish. In addition, AABB patterns could be developed together by cutting out squares of baby animals or lining up miniature farm animals to create patterns of baby animals. During both math activities, the math helpmate may redirect questions or reinforce another child's strengths by praising and giving positive feedback to a child when an activity is complete. By doing this, a child can learn that their peers have motivating methods and ideas that are significant and can contribute to his or her interests and passions as well (Drew \& Baji, 2004).

Research confirms young children can be trained problem-solving skills successfully (Webster-Stratton \& Hammond, 1997; Shure \& Spivack, 1980). During math sharing activities, math helpmates can employ four easy steps for problem solving. The steps include: (a) what is the math problem we are working on together? (b) what are some solutions to the math problem? Let's work together to find out; (c) what could occur next? and (d) let's try the solution together! During this entire process, teachers should observe, document, and be close by to answer questions and anticipate any unexpected problems; support both the math tutor and child learning the math skills by providing additional examples using visuals cues and scripts for helpmates or elaborating on initial interactions between the math tutor and child; encourage with positive reinforcements such as stickers, recognition awards and/or cheers; and promote confidence and success with a verbal gesture such as, "You did it," "You are a math Superstar," or nonverbal gesture with a thumbs up, high-five sign, a wink, and/or smile (Joseph \& Strain, 2010). Children's interests, new ideas and discoveries can emerge when their curiosity is sparked, which may encourage young children to explore and investigate materials together (Rosales, 2015).

\section{Teachers' Supporting Role}

For successful math helpmates with peers, teachers should consider very carefully the activity and math skill for both the math helpmate and child receiving the assistance and support. The goal for teachers is to develop math instruction with peers that is connected to concepts the children wish to investigate (Rosales, 2015). Create opportunities for success by training and role modeling with the math helpmate regarding how to request information and commence math activities, comment and ask questions, direct and prompt math interactions, and reinforce math solutions with his math partner. Math helpmates need to know how to be responsive an encourage conversations (Bambara, Thomas, Chovanes, \& Cole, 2018). Accommodating training strategies may include pictorially based stories, visual scripts, activity schedules, peer journals, sequence strips, puppets, role-modeling videos, or visual cues using digital photos. Using visual schedules with drawings, photos, and words during training can give the child a concrete idea of what will happen next (Brillante, 2017). Visual supports should be individualized to support the target math skill and also match the child's capabilities (Bambara, Thomas, Chovanes, \& Cole, 2018). There are a variety of developmentally appropriate formats for young children including cue cards, communication books, and tablets. Math helpmates can also become more approachable and open to responses by learning three basic conversation strategies: (a) showing interest in what the other child says by smiling, acknowledging the child, and responding to questions; (b) asking open-ended questions to share information about a math activity and taking turns; and (c) assisting the other child to respond by re-asking a question or gaining attention with eye contact and rephrasing a question to understand easier (Bambara, Chovanes, Thomas, \& Cole, 2016).

Teachers should also be thoughtful and considerate when pairing students. It's important for teachers to consider children's strengths, temperament traits, interests, and characteristics into consideration when pairing children with math helpmates. For example, pairing a child that demonstrates a stronger understanding of math concepts with a child who is less advanced in their mathematical understanding gives a less functioning child in math opportunities to imitate and learn through observations and interactions with a stronger peer (Tudge, Winterhoff, \& Hogan, 1996). A child can be paired to support each other think through a problem and this has the potential to promote thinking while talking (Bodrova \& Leong, 1996). Additional ways for planning effective math peer-shared activities is making sure each child has an assigned role to complete during the math activity and consider creating additional opportunities for math play with a variety of learning centers including pretend play, a variety of different types of blocks, literacy center featuring picture books with an emphasis on math concepts, mobile technology using iPads, and science experiments. Teacher's prompts and questions during math activities and discussions should be short and concrete. It's important to show and demonstrate to the math helpmate how to initiate conversations with a child and teach how to model a math problem. Before beginning a new project or special math event, such as a math carnival, a teacher should take time to train math 
helpmates in small groups and also one-on-one by modeling ways notice and create patterns. For example, taking time before class or during recess to go over the activities with the math helpmates and role play practicing math scenarios such as using fractions by making a "positive math pizza," sorting blocks by color, size, and shape, and creating a number sequence by counting the number of tickets for a math carnival can support the math helpmate to feel confident in his/her role and also may increase greater academic achievement and class participation. It is also important to consider using children's preferences during math activities to motivate and support more effectively to communicate their ideas about problems to their peers (Burton, 2012). Math helpmates also have the potential to provide individualized support, especially introducing routine transitions during math activities, and can support the learning of megacognitive skills (i.e., planning how to think about something) for a deeper understanding of math content (Cohen, Kulik, \& Kulik, 1982).

\section{Math Transitions}

Transition activities are teaching techniques and are used to prepare children to listen or move from place to place and activity to activity (Hemmeter, Ostrosky, Artman, \& Kinder, 2008). Transition activities differ from regular activities in purpose, length, and frequency, but they require the same consideration and planning (Hildebrand, 1981). Rosenkoetter and Fowler (1986) suggest that teachers plan for skill building during transition time just as one would for other activities. Teachers frequently report that transitions between activities (Barnett, Bell \& Carey, 1999) create difficulties in the classroom. During this shift of focus, some children are unable to maintain their sense of purpose and direction (Davis, Reichle, \& Southard, 2000). For example, inadequate warnings for the next math activity, changes in activity levels, and increased noise may trigger opportunities for challenging behaviors for all young children. Improving the ability of preschool children to make independent transitions within inclusive classroom settings during math activities may help children to prepare them for successful experiences in less restrictive environments. It is important to identify strategies that can be implemented or adapted to help children for whom transitions trigger challenging behaviors (Crosser, 1992).

During transitions, math helpmates could act as transition time monitors or can prompt and initiate a child to transition into the next activity. For example, during a math carnival a math helpmate could increase physical and social proximity by taking a child's hand and walking together to different learning centers and activities. The math helpmate could assist the child with measuring activities and recording estimates on a recording sheet. Another way a math helpmate can increase social proximity during transitions is moving in different ways to create movement patterns. For example, the class could repeat a pattern with their math helpmates during a musical movement activity by doing up and down movements for a carousel ride during the math carnival. Each child would have a carousel pony made from paper and a straw and could create the movement patterns such as going up and down; right and left; and forwards and backwards. Storyboards, puppets, and social stories are also helpful tools for math helpmates during transitions to use as prompts for classmates. An example of this type of transition would be having a puppet announce clean up time to the class before the next activity during the math carnival or supporting a child one-on-one by picking up toys. Math helpmates who act as transition peer monitors not only support and empower a child during math transitions, they also free the teacher from some supervisory responsibilities as well as receive various social benefits and acquire leadership skills (Strain, 1981). Teachers may assign responsibilities that encourage social interactions. For example, a math help mate could be responsible for counting together before going to outdoor play or for counting the days of the week on a calendar. Although transition times may often be viewed as "down times" in an early childhood inclusive classroom, transitions provide opportunities for children to practice existing or new target skills, such as math, and also have opportunities for positive outcomes for social and communicative interactions and conversations with peers.

\section{Math Chats}

Communication is essential for learning. Mathematical communication is an avenue of sharing ideas and illuminating understanding (NCTM, 2010). Math chats is another strategy for encouraging peer interactions during peer-shared activities. Teacher interactions during math chats are positive and can encourage children's development of mathematical process skills (Tyminski \& Linder, 2012). Often, children who have trouble learning math often require the teacher to model mathematics principles while explaining what is happening and why (Witzel, Ferguson, \& Mink, 2012). Math is a time for conversations! Therefore, it is important to have interactions for ideas and "peer and partner chats" during math activities for young children. This type of interactive, natural communication refers to specific guidance and helpful hints teachers can provide during math activities to support children with a positive attitude to become better problem solvers and more confident with math skills. Teachers can use math chats in many situations to draw attention to math concepts and interest during play or planned activities (Tyminski \& Linder, 2012). During teacher math chats, encourage different ways of thinking. Ask children, "Does anyone have a different idea?" Teachers can also consider questions that invite children to observe closely. For example, during the math carnival, a teacher may ask children, "What patterns do you notice?" "What do you predict?" And "How can you show me and your math 
helpmate this pattern?" By encouraging their participation, you'll not only learn more about individual children's thinking, but you'll also give the message to children that there is more than one way to solve a problem. During math chats, teachers can guide the discussions and conversations to support a child clearly describe their problem-solving steps and strategies (Burton, 2012). You will give children opportunities to succeed and feel confident!

Math chats has several components for encouraging, motivating, and participating (Sharpe, 2008). The components include: rephrasing and restating the directions to a math activity so the fully child understands; expanding on the directions and type of math skills being taught with examples and/or what a child has said by offering several different ways to experience a concept; questioning with open-ended questions to encourage problem solving. During this step, teachers can help children develop problem-solving skills by posing questions and making comments. For example, teachers can extend children's observations by asking the class, "How might we test your idea out?"; "How are they alike?" or "How are they different?" Math helpmates can become more approachable and open to responses by learning three basic conversation strategies: (a) showing interest in what the other child says by smiling, acknowledging the child, and responding to questions; (b) asking open-ended questions to share information about a math activity, encouraging initiations, and taking turns; and (c) assisting the other child to respond by re-asking a question or gaining attention with eye contact and rephrasing a question to understand easier (Bambara, Chovanes, Thomas, \& Cole, 2016).

During math chats, it is also important for teachers to take a step back allowing the child to process the information. Ask children to consider new ways of approaching problems. For example, encourage children to use math manipulatives (for example: interlocking cubes, pattern blocks, and teddy bear counters) to solve a problem and then reflect on and rationalize their solutions. During the math carnival, children could represent patterns with drawings and also share pattern picture books with math helpmates. Additional ways to approach problem solving may include creating a list of vocabulary words and phrases during a math chat. After the math chat, teachers may post the vocabulary words and phrases on a bulletin board and refer to them often. Use the language of mathematics to convey mathematical ideas accurately.

Math chats could also be very appropriate for those children who feel uncomfortable or have difficulty interacting with a math helpmate. Teachers can develop math chats using open-ended questions regarding number concepts, patterns, measurement, geometry, spatial reasoning, and data analysis and prompts to develop, monitor, and promote social interactions during math play and instruction. Ask "why," "why not," and "what if?" For example, "what do you notice about?" or "How can we figure this out?" Such type of open-ended questions can encourage children to attend to and describe mathematical objects. It may also give children opportunities to think more deeply about a math concept or idea. The critical significance of developing children's reasoning processes and capability to symbolize, converse, and connect ideas cannot be overestimated (Heirdsfield, 2012). For this reason, it is important to identify opportunities for using math chats during your daily routines and transitions throughout the day. It is also important to build on children's varying experiences, including their family and cultural backgrounds. Varied opportunities offering multiple expressions can nurture children's dispositions and confidence regarding math and also increase multiple approaches for understanding (Whitin, P. \& Whitin, D., 2011). Teachers can ask children questions regarding math standards that have the possibility to engage them in dialogue to promote connecting to and building on various strategies (Burton, 2012). An important consideration for teachers is to demonstrate the math that occurs in daily life concrete and visible to young children (Greenberg, 2012). When teachers invite children to participate about things that are important to them, children are more likely to become engaged in the data analysis process (Burton, 2012).

\section{Incidental Teaching}

In addition to the communication skills during math chats, the classroom environment also can relate to children's learning and development (Kontos, 1999). The third strategy to consider for increasing critical thinking during peer-shared activities is incidental teaching. Many important social skills are introduced and achieved during day-to-day interactions with peers through incidental teaching (Rathvon, 2008). Incidental teaching is an approach to teaching new skills within natural environments and continuing routines and activities (McGee, Daly, \& Jacobs, 1994). Incidental teaching is a milieu teaching strategy based on naturally occurring classroom events (Kamps, Kravits, \& Ross, 2002). During incidental teaching, the child takes the lead and initiates social interactions with peers and/or the teacher (Warren, Yoger, \& Lewis, 2002). As the interactions begin, the teacher establishes a joint attention and prompts for desired responses either verbally (usually a direct command) or nonverbally. Steps for establishing incidental teaching are listed below in Table 1 . 
Table 1. Steps for Using Incidental Teaching Strategy for Promoting Peer-Shared Interactions

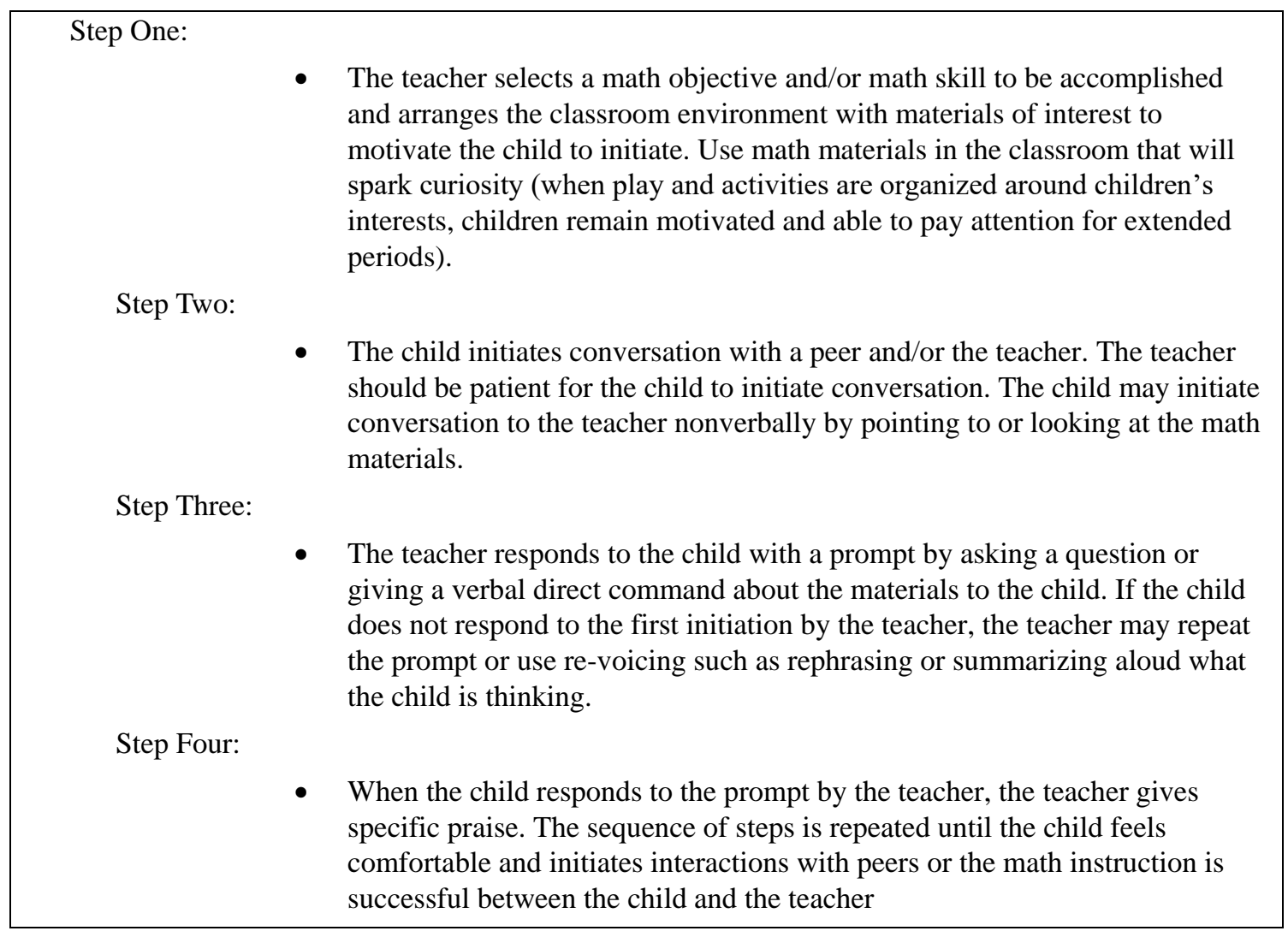

Source: Adapted from G. G. McGee, M. J. Morrier, and T. Daly (1999): An incidental teaching approach to early intervention for toddlers with autism. (The Journal of the Association for Persons with Severe Handicaps, 24 no. 3), pp. $133-146$.

When using incidental teaching strategies, authentic math explorations should be scheduled during the day time for collaborative and play-based learning. Teachers should support children in considering connections of ideas within mathematics as well as other early childhood content areas, developing their mathematical knowledge throughout the school day and across the curriculum (NCTM Position Statement, 2013). For example, create graphs of classroom activities and make maps together. Focus on spatial concepts and terms. Invite children to notice similarities and differences every day. Through careful observations, teachers should take time to incorporate children's interests into the math curriculum. This will encourage a stronger anticipatory hook for a child to initiate social interaction with peers. For successful incidental teaching to occur, it is important for teachers to personalize the classroom for children whenever possible. Teachers should consider using hands-on activities and establishing opportunities for math chats in a variety of math learning centers to motivate children and response to another child's initiation. For example, math helpmates can classmates with making mini ice-cream cone patterns after reading together 10 Scoops of Ice-cream; A delicious counting book. After the story, children can have the opportunity to visit the math center and place different color pom-poms (scoops) on cardboard waffle cones to form AB, ABC and AABB patterns. In addition, children had the opportunity with their math helpmate to create additional patterns using iPads with Web 2 apps. Invite children to suggest math investigations and to identify open-ended materials they need to further their explorations. Allow children to surprise you! As you read stories, converse about numbers and patterns you see in books. During music, count and clap to the number of beats to a song and look for interesting shapes when creating a rhythm band. Focus on a variety of children's songs that are many times based on simple repeating rhythmic patterns. Use dance and movement to promote pattern activities. For example, many dance steps are based on numerical patterns. During outdoor play, children can take walks around the neighborhood of the school and look for patterns in nature. Name groups of objects with numerals and identify shapes.

\section{Discussion}

Peer-shared activities represent just one component of a comprehensive educational program for young children in inclusive settings (Carter, Cushing, \& Kennedy, 2009). In addition, peer-shared activities is an evidence-based practice, shown to be effective for a wide range of social skills for children across all developmental ages (Wong, Odom, Hume, 
Cox, Fettig, Kucharczyk, \& Schultz, 2015). For peer-shared activities to be successful and significant for a young child, teachers need to be enthusiastic about the content area being taught. Teamwork is essential! For example, when teachers promote excitement and interest in math, children can gain confidence and promote math growth in their abilities (Burton, 2012). The role of teachers is to scaffold and facilitate math learning by offering opportunities and materials in an environment to promote critical mathematical thinking. Peer-shared activities is not automatic; it takes time, thoughtful planning, and adult guidance. The effectiveness of peer-shared activities does not imply the role of the teacher is no longer needed (Carter, Cushing \& Kennedy, 2009). Peer-shared activities work best when accompanied by reflective planning and guidance by teachers. To maximize success when using peer-shared strategies, teachers should be actively involved in monitoring math progress, providing feedback to children, and supporting peer interactions. Peer relationships are very important, especially for teaching math concepts. Children expand their minds cognitively and their relationships socially from observing, collaborating with, and learning from their peers (Shillady, 2012). Sometimes, it may take peer-shared experiences longer time to be effective. This could be for several reasons including whether the math helpmates are responsive and receptive to trainings, if there are shared interests among math helpmates and the child(ren) receiving math support, and whether the math helpmates feel confident using new skills to support new friends. If this should occur, teachers could consider identifying different times during the day for presenting math concepts, rotating new peers to become math helpmates, provide additional coaching and training and switching visual supports from visual cards to social stories or social scripts. It is important to be creative, innovative, and include a spark of fun into the superpowers of learning math for all children, including the math helpmates.

\section{Conclusion}

Math is everywhere for a young child. Young children have an intrinsic understanding of and awareness in mathematics (Shillady 2012). Early childhood teachers have the opportunity to introduce children to the new discoveries and applications it has in their daily lives. There are multiple opportunities during the day for children to hear new math vocabulary and extend their understanding of math concepts (Greenberg, 2012). Peer-shared activities, including math helpmates and math chats, can offer a hopeful approach for supporting math experiences for young children in inclusive classroom settings. Supporting the social and emotional development of young children along with mathematical development is crucial in all early childhood classroom (Institute of Medicine (IOM) \& National Research Council (NRC), 2015). Collaboration with peers can also support a democratic classroom culture that encourages social justice through shared engagement and small group learning (Rosales, 2015). As young children acquire new math concepts and vocabulary, they may incorporate this new knowledge into their play experiences, which may enhance their social and emotional development (Platas, 2017). Play experiences are significant for exploration, investigation, role-playing and builds math knowledge for young children they can use later in elementary grades (Rosales, 2015). Inviting a math helpmate to explain to a peer how or why they arrived at an answer or to show a different way to find an answer during math activities supports children to communicate and better understand their own thinking (Burton, 2012). Strategies contributing to social skills groups, such as peer-shared activities, can contribute significantly to a child's development, which can lead to the possibility of rewarding social interactions (Sartini, Knight, \& Collins, 2013). Role-playing, modeling, prompting peer interactions, and providing specific feedback are all ways of encouraging peer interactions during peer-shared activities. Young children can be sophisticated mathematical critical thinkers and problem solvers. When young children are given developmentally appropriate and intentional opportunities to share interests about math with peers, self-confidence regarding math increases for all young children with a greater sense of accomplishment.

Meaningful math experiences for young children is just as exciting as enjoying a Cracker Jack snack at a math carnival. After eating the caramel-coated popcorn and peanut treats, a surprise is revealed at the bottom of the box. The similar fun, surprise, and excitement of a new discovery can be captured by a young child when learning new math concepts using peer-shared activities.

\section{References}

Bahr, D. L., \& deGarcia, L. A. (2010). Elementary mathematics is anything but elementary: Content and methods from a developmental perspective. Belmont, California: Wadsworth Cengage Learning.

Bambara, L. M., Chovanes, J., Thomas, A., \& Cole, C. L. (2016). Effective peer-mediated strategies for improving the conversational skills of adolescents with autism. Perspectives of the ASHA Special Interest Groups, 1, 29-36. https://doi.org/10.1044/persp1.SIG1.29

Bambara, L. M., Thomas, A., Chovanes, J., \& Cole, C. L. (2018). Peer-mediated intervention: Enhancing social conversational skills of adolescents with autism spectrum disorder. Teaching Exceptional Children, 51(1), 7-17. https://doi.org/10.1177/0040059918775057

Barnett, D. W., Bell, S. H., \& Carey, K. T. (1999). Designing preschool interventions: A practitioner's Guide. New York: The Guilford Press. 
Baroody, A. J., Lai, M. L., \& Mix, K. S. (2006). The development of young children's number and operation sense and its implications for early childhood education. In Handbook of Research on the Education of Young Children, B. Spodek \& O. N. Saracho, Eds. pp. 187-221. Mahwah, NJ: Erlbaum.

Bodrova, E., \& Leong, D. J. (1996). Tools of the mind: The Vygotskian Approach to Early Childhood Education. Englewood Cliffs, New Jersey: Prentice Hall.

Brillante, P. (2017). The essentials: Supporting young children with disabilities in your classroom. Washington, D.C.: National Association for the Education of Young Children.

Burton, M. (2012). Five strategies for creating meaningful mathematics experiences in the primary years. In Spotlight on young children: Exploring math. Edited by Amy Shillady, pp. 10-14. Washington, D.C.; National Association for the Education of Young Children.

Carter, E. W., Cushing, L. S., \& Kennedy, C. H. (2009). Peer support strategies for improving all students' social lives and learning. Baltimore, MD: Brookes.

Cohen, E. W., Kulik, J. A., \& Chen-Lin, C. K. (1982). Educational outcomes of tutoring: A meta analysis of findings. American Educational Research Journal 19 (2): 237-248. https://doi.org/10.3102/00028312019002237

Copley, J. V. (2004). The young child and mathematics. Reston, Virginia: National Council of Teachers of Mathematics.

Crosser, S. (1992). Managing the early childhood classroom. Young Children, 47(2), 23-29.

Davis, M. D., Kilgo, J. L., \& Gamel-McCormmick, M. (1998). Young children with special needs: A developmentally appropriate approach. Boston, MA: Allyn and Bacon.

Denham, S. A., Blair, K. A., Demulder, E., Levitas, J., Sawyer, K., \& Auerbach-Major, A. (2003). Preschool emotional competence: Pathway to social competence? Child Development, 74, 238-256. https://doi.org/10.1111/1467-8624.00533

Diamond, K. E., Hong, S. Y., \& Baroody, A. E. (2008). Promoting young children's social competence in early childhood programs. In W. H. Brown, S. L. Odom, and S. R. McConnell (Eds.), Social competence of young children: Risk, disability, and intervention, (pp. 165-184). Baltimore: Brookes.

Drew, W. F., \& Baji, R. (2004). Promoting creativity for life using open-ended materials. Young Children, 57 (July):1-8.

Elias, M. J., \& Dilworth, J. E. (2003). Ecological developmental theory, context-based best practice and school-based action research: Cornerstones of school psychology training and policy. Journal of School Psychology, 41, 293297. https://doi.org/10.1016/S0022-4405(03)00050-5

Emmer, E. T., \& Gerwels, M. C. (2002). Cooperative learning in elementary classrooms: teaching practices and lesson characteristics. Elementary School Journal, 103, 75-91. https://doi.org/10.1086/499716

Epstein, A. S. (2014). The intentional teacher: Choosing the best strategies for young children's learning. Ypsilanti, Michigan: High Scope Press.

Gilberts, G. H., Agran, M., Hughes, D., \& Wehmeyer, M. (2001). The effects of peer delivered self-monitoring strategies on the participation of students with severe disabilities in general education classrooms. Journal of the Association for Persons with Severe Handicaps, 26(1), 25-36. https://doi.org/10.2511/rpsd.26.1.25

Gordon, P. A., Feldman, D., \& Chiriboga, J. (2005). Helping children with disabilities develop and maintain friendships. Teacher Education and Special Education, 28(1), 1-9. https://doi.org/10.1177/088840640502800101

Greenberg, J. (2012). More, all gone, empty, full: Math talk every day in every way. Young Children, 67(3), 62-64.

Heirdsfield, A. M. (2012). Teaching mental computation strategies in the primary grades. In Spotlight on young children: Exploring math. Edited by Amy Shillady, pp. 42-48. Washington, D.C.: National Association for the Education of Young Children.

Hemmeter, M. L., Ostrosky, M. M., Artman, K. M., \& Kinder, K. A. (2008). Moving right along: Planning transitions to prevent challenging behavior. Young Children, 61(3), 1-7.

Hildebrand, V. (1981). Introduction to Early Childhood Education. New York: Macmillan.

IOM (Institute of Medicine) \& NRC (National Research Council). (2015). Transforming the work place for children birth through age 8: A unifying foundation: Washington, DC: The National Academic Press.

Jackson, J. (2012). Partnering to bring social and learning to school. Commentary. Social Policy Report, 26(4), $27-28$.

Joseph, G. E., \& Strain, P. S. (2003). Enhancing emotional vocabulary in young children. Young Exceptional Children, 6 (August), 18-27. https://doi.org/10.1177/109625060300600403 
Jung, M., \& Conderman, G. (2015). Using digital technology to support mathematics instruction. Young Children, 70 (May), 64-69.

Kamps, D. M., Kravits, T., \& Moss, R. (2002). Social-communicative strategies for school-age children. In Promoting social communication: Children with devlopmental disabilities from birth to adolescence. Edited by H. Goldstein, L.A. Kaczmarek, and K. M. English, pp. 239-277. Baltimore, Maryland: Brookes.

Kontos, S. (1999). Preschool teachers' talk, roles, and actively settings during free play. Early Childhood Research Quarterly, 14(3), 363-382. https://doi.org/10.1016/S0885-2006(99)00016-2

Ladd, G. W. (2007). Social learning in the peer context. In O. N. Saracho and B. Spodek (Eds.), Contemporary perspectives on socialization and social development in early childhood education (pp. 133-164). Charlotte, NC: Information Age Publishing.

Lynch, S. A., \& Warner, L. (2013). How adults foster young children's intellectual development. Young Children, 68(2), $86-91$.

McGee, G. G., Daly, T., \& Jacobs, H. A. (1994). The Walden preschool in Massachusetts. Preschool education programs for children with autism. Austin, Texas: PRO-ED:

McGee, G. G., Morrier, M. J., \& Daly, T. (1999). An incidental teaching approach to early intervention for Toddlers with autism. The Journal of the Association for Persons with Severe Handicaps, 24(3), 133-146. https://doi.org/10.2511/rpsd.24.3.133

National Council for Teachers of Mathematics (NCTM). 2013. Mathematics in early childhood learning: A position of the National Council of Teachers of Mathematics.

http://www.nctm.org/uploadedFiles/Standards_and_Positions/Position_Statements/Early\%20Childhood\%20Mathe matics\%20(2013).pdf

National Council for Teachers of Mathematics. (2010). Standards for pre-K-12 mathematics. Executive summary: Principles and standards for school mathematics. http://www.nctm.org/uploadedFiles/Standards_and_Positions/PSSM_ExecutiveSummary.pdf

Platas, L. M. (2017). Three for one. Supporting social, emotional, and mathematical development Young Children, 72(2), $33-37$.

Rathvon, N. (2008). Effective school inventions: Evidence-based strategies for improving student outcomes. New York: Guilford.

Rosales, A. C. (2015). Mathematizing: An emergent math curriculum approach for young children. St. Paul, MN: Redleaf Press.

Rosenkoetter, S. E., \& Fowler, S. A. (1986). Teaching mainstreamed children to manage daily transitions. Teaching Exceptional Children, 19, 20-23. https://doi.org/10.1177/004005998601900104

Sartini, E. C., Knight, V. F., \& Collins, B. C. (2013). Ten guidelines to facilitate social groups for students with complex special needs, 45(3), 54-62.

Saunders, S. A., \& Green, V. (1993). Evaluating the social competence of young children: A review of the literature. Early Child Development and Care, 87, 39-46. https://doi.org/10.1080/0300443930870104

Sharpe, T. (2008). How can teacher talk support learning? Linguistics and Education, 19, 132-148. https://doi.org/10.1016/j.linged.2008.05.001

Shillady, A. (2012). Math is everywhere! Tips for mathematizing preschool settings. In Spotlight on young children: Exploring math. Edited by Amy Shillady, pp. 34-35. Washington, D.C: National Association for the Education of Young Children.

Shure, M. B., \& Spivack, G. (1980). Interpersonal problem solving as a mediator of behavioral adjustment in preschool and kindergarten children. Journal of Applied Developmental Psychology, 1, 29-44. https://doi.org/10.1016/0193-3973(80)90060-X

Solomon, G. (1993). Distributed cognitions: Psychological and educational considerations. Cambridge, Massachusetts: Cambridge University Press.

Strain, P. S. (1981). The utilization of classroom peers as change agents. New York: Plenum. https://doi.org/10.1007/978-1-4899-2180-2

Terpstra, J. E., \& Tamura, R. (2008). Effective social interaction strategies for inclusive settings. Early Childhood Education Journal, 35(5), 405-411. https://doi.org/10.1007/s10643-007-0225-0 
Tudge, J. R., Paul, H., Winterhoff, A., \& Hogan, D. M. (1996). The cognitive consequences of collaborative problem solving with and without feedback. Child Development, 7, 2892-2909. https://doi.org/10.2307/1131758

Tyminski, A. M., \& Linder, S. M. (2010). Encouraging preschoolers' emerging mathematical skills. In Spotlight on young children: Exploring math. Edited by Amy Shillady, pp. 28-33. Washington, D.C.: National Association for the Education of Young Children.

Wakefield, A. P. (1997). Support math thinking. Phi Delta Kappan (November), 233-236.

Warren, S. F., Yoder, P. J., \& Lewis, S. V. (2002). Promoting social communication development in Infants and toddlers. In Promoting social communications: Children with developmental Disabilities from birth to adolescence. Edited by L. A. Goldstein, L. A. Kaczmarek, and K. M. English, pp. 121-149. Baltimore, Maryland: Brookes.

Webster-Stratton, C., \& Hammond, M. (1997). Treating children with early-onset conduct problems: A Comparison of child and parent training interventions. Journal of Consulting and Clinical Psychology 65(1), 93-109. https://doi.org/10.1037/0022-006X.65.1.93

Wentzel, K. R. (1991). Social competence at school: Relation between social responsibility and academic achievement. Review of Educational Research, 61(1), 1-24. https://doi.org/10.3102/00346543061001001

Whitin, P., \& Whitin, D. J. (2011). Mathematical pattern hunters. Young Children, 66(3), 84-90.

Witzel, B. S., Ferguson, C. J., \& Mink, D. V. (2012). Number sense: Strategies for helping preschool through grade 3 children develop math skills. Young Children, 67(3), 89-94.

Wong, C., Odom, S. L., Hume, K. A., Cox, A. W., Fettig, A., Kucharczyk, S., \& Schultz, T. R. (2015). Evidence-based practices for children, youth, and young adults with autism spectrum disorder: A comprehensive review. Journal of Autism and Developmental Disorders, 45, 1951-1966. https://doi.org/10.1007/s10803-014-2351-z

Zaslow, M. (2014). General features of effective professional development: Implications for preparing early educators to teach mathematics. In Preparing Early Childhood Educators to Teach Math: Professional Development that Works. Eds. H. P. Ginsburg, M. Hyson, \& T. A. Woods, pp. 97-115. Baltimore, MD: Brookes.

\section{Copyrights}

Copyright for this article is retained by the author(s), with first publication rights granted to the journal.

This is an open-access article distributed under the terms and conditions of the Creative Commons Attribution license which permits unrestricted use, distribution, and reproduction in any medium, provided the original work is properly cited. 